\title{
Design and Implementation of a Simulator for Photovoltaic Modules
}

\author{
Kuang-Hui Tang, Kuei-Hsiang Chao, Yuan-Wei Chao, and Jyun-Ping Chen \\ Department of Electronic Engineering, National Chin-Yi University of Technology, No. 57, Section 2, Zhongshan Road, \\ Taiping District, Taichung 41170, Taiwan \\ Correspondence should be addressed to Kuei-Hsiang Chao, chaokh@ncut.edu.tw
}

Received 4 October 2011; Revised 11 December 2011; Accepted 11 December 2011

Academic Editor: F. Yakuphanoglu

Copyright (๑) 2012 Kuang-Hui Tang et al. This is an open access article distributed under the Creative Commons Attribution License, which permits unrestricted use, distribution, and reproduction in any medium, provided the original work is properly cited.

\begin{abstract}
Proposed in this paper is the development of a photovoltaic module simulator, one capable of running an output characteristic simulation under normal operation according to various electrical parameters specified and exhibiting multiple advantages of being low cost, small sized, and easy to implement. In comparison with commercial simulation tools, Pspice and Solar Pro, the simulator developed demonstrates a comparable $I-V$ as well as a $P-V$ output characteristic curve. In addition, a series-parallel configuration of individual modules constitutes a photovoltaic module array, which turns into a photovoltaic power generation system with an integrated power conditioner.
\end{abstract}

\section{Introduction}

Among various renewable energy sources, for example, wind power, solar energy, geothermal power, and hydropower, the solar energy is the promising one most widely applied in practice, on account of advantages of (1) being environmentally friendly, (2) low system maintenance cost, (3) wide application, and (4) inexhaustible solar energy supply.

A photovoltaic power generation system refers to a system mainly composed of a power conditioner, a power transmission and distribution system, and a photovoltaic module as the key component therein. An incident solar energy on the photovoltaic module is converted into an electricity output, and a photovoltaic module array is configured in either series or parallel according to the load end or the level of the input voltage or current specified to the power conditioner. However, up to now the photovoltaic power generation system consists of costly components, making a destructive testing infeasible such as tests on module malfunction, electrical shock and lightning strike incidents due to budget concerns. Besides, an application of such power generation system to a power converter through a well-designed controller yields a well-performed electricity output to load end. Hence, it is an immediate issue of significance to develop a model for a photovoltaic module, further extended to an array, to accurately simulate the output voltage waveform as intended under various system configurations.

Applied to a power generation system of such type, there had been a great number of modeling technologies developed, such as those [1-3] for real-time weather detection. However, owing to a rapid change in atmospheric conditions, it is unlikely to apply such technology to data measurement and even comparison in an identical atmospheric context, and a scalability of the subsequent system capability is limited for the reason that the measurement is conducted mostly in a hardware system. The photovoltaic module is alternatively simulated by a number of such packages as SPICE [4-7], SABER [8, 9], and EMTP [10]. Modeled in part as nonlinear elements, the equivalent circuit of such module requires a long period of simulation time, and by no means precisely describes the electrical behavior of such module owing to the grounding requirement imposed on the power components. Performing a simulation through an equivalent equation in a conventional manner, ESLIN [11] is of an advantage of an efficient computation, but a disadvantage of being short of the electrical behavior description. Another disadvantage is that numerical analysis is required to solve the nonlinear equivalent equation for an intended solution. 


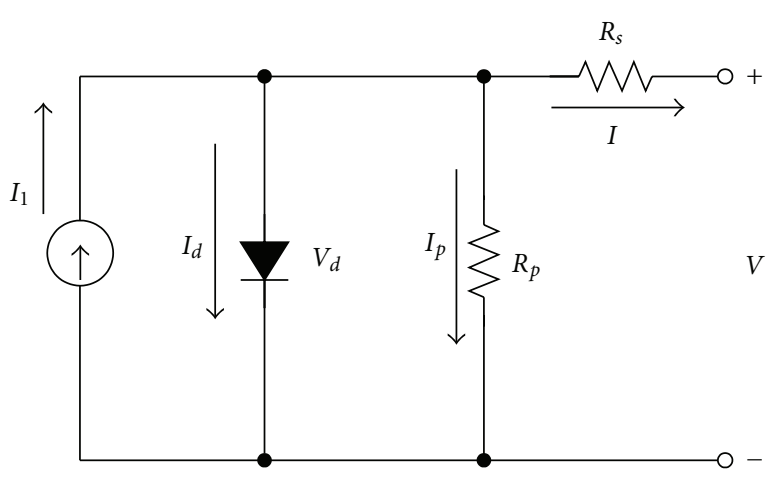

FIGURE 1: Equivalent circuit of a solar cell.

Moreover, the module simulation can also be made by some sorts of algorithms, for example, fuzzy [12], neural [13], neural-fuzzy [14], and so forth, for those lacking the physical understanding of electrical parameters, but the disadvantage is that it is for sure not an easy task to find the solution, in particular the optimal solution. This results in not exactly the optimized model accordingly. Apart from that, developed based upon previously measured data, such model cannot be applied to simulations for other cases or systems with extended capability.

In order to overcome the inconvenience in laboratory experiments of a photovoltaic power generation system, a photovoltaic module simulator having identical output $I-V$ and $P-V$ characteristics as a practical photovoltaic module was developed in this paper. The developed photovoltaic module simulator implemented with analog circuits can be used on various types of series-parallel connection to form a photovoltaic module array for performing experiments on maximum power point tracking (MPPT) studies.

\section{An Equivalent Circuit of a Solar Cell}

Regarded as an unbiased component having a P-N junction, a solar cell turns the incident energy into a photocurrent. During the energy conversion, electrons, confined in the valence band (VB) and pumped by incident photons, jump to the conduction band (CB) and in the end form the photocurrent, collected by an electrode. Illustrated in Figure 1 is an equivalent circuit of a solar cell [15].

According to the Kirchhoff's Law, the relationship between various currents in the solar cell is expressed in (1), with each current defined in (2) to(4)

$$
I=I_{l}-I_{d}-I_{p}
$$

where $I_{l}$ : the photocurrent source at a specified irradiation and temperature, $I_{d}$ : the diode current, and $I_{p}$ : the current flowing through a parallel resistor caused by a flawed P-N junction.

$$
I_{l}=\left[I_{\mathrm{sc}}+k_{i}\left(T_{s}-T\right)\right] \frac{S_{i}}{1000}
$$

where $T_{s}$ : the surface temperature of the solar cell, $S_{i}$ : the irradiation incident on the solar cell, $I_{\mathrm{sc}}$ : the short circuit current at $1,000 \mathrm{~W} / \mathrm{m}^{2}$ and $25^{\circ} \mathrm{C}$, and $k_{i}$ : the temperature modification coefficient for the short circuit current.

$$
\begin{gathered}
I_{d}=I_{\mathrm{sat}}\left[\exp \left(q \frac{\left(V+I R_{s}\right)}{A K T}\right)-1\right], \\
I_{p}=\frac{V_{d}}{R_{p}}=\frac{V+I R_{s}}{R_{p}},
\end{gathered}
$$

where $I_{\text {sat }}$ : the reverse saturation current at a specified temperature for the solar cell junction, $V$ : the solar cell output voltage, $A$ : an ideal parameter roughly between 1 and $5, K$ : the Boltzmann constant $\cong 1.3806 \times 10^{-23} \mathrm{~J} / \mathrm{K}, T$ : the reference temperature $=298 \mathrm{~K}, q$ : an electron charge $=1.6022 \times$ $10^{-19} \mathrm{C}, R_{s}$ : the equivalent internal series resistor, and $R_{p}$ : the equivalent internal parallel resistor due to a flawed $\mathrm{P}-\mathrm{N}$ junction.

The reverse saturation current $I_{\text {sat }}$ is affected by the junction temperature, expressed as

$$
I_{\text {sat }}=I_{\mathrm{rr}}\left(\frac{T_{s}}{T}\right)^{3} \exp \left\{\frac{q E_{\mathrm{gap}}}{K A}\left(\frac{1}{T}-\frac{1}{T_{s}}\right)\right\},
$$

where $I_{\text {rr }}$ represents the reverse saturation current at $25^{\circ} \mathrm{C}$ $(298 \mathrm{~K})$ and $E_{\text {gap }} \cong 1.1 \mathrm{eV}$ the energy gap for an Si semiconductor.

All the equations referred to above are a mathematic representation for a single solar cell. In order to express the relationship between the voltage and current for a photovoltaic module configured in various series-parallel connections, the characteristic equation is modified into

$$
\begin{aligned}
I\left(1+\frac{R_{s}}{R_{p}}\right) & =n_{p} I_{l} \\
& -n_{p} I_{\text {sat }}\left\{\exp \left[\left(\frac{q}{\mathrm{AKT}}\right)\left(\frac{V}{n_{s}}+I R_{s}\right)-1\right]\right\} \\
& -\frac{\left(V-n_{s}\right)}{R_{p}},
\end{aligned}
$$

where $n_{s}$ and $n_{p}$ denote the number of solar cells connected in series and in parallel, respectively.

Adopted in this work as a simulation object, the SANYO HIP 2717 solar cell [16], fabricated with heterojunction made by the intrinsic thin layer (HIT) technology, is a module consisting of 32 cells connected in series, with an output power rated at $27.87 \mathrm{~W}$. Tabulated in Table 1 are the electrical parameters specification at an irradiation of 1,000 $\mathrm{W} / \mathrm{m}^{2}$, AM1.5, and a module temperature of $25^{\circ} \mathrm{C}$ under standard test conditions (STC), and plotted in Figures 2(a) and $2(\mathrm{~b})$ are the $I-V$ and $P-V$ output characteristic curves for the module.

\section{Existing Study and Explore}

In [17], the equivalent circuit of a solar cell is modeled as a number of diodes connected in parallel in an attempt to describe the cell nonlinearity. As illustrated in Figure 3, the nonlinear $I-V$ characteristic is approximated as $2^{K}$ number 


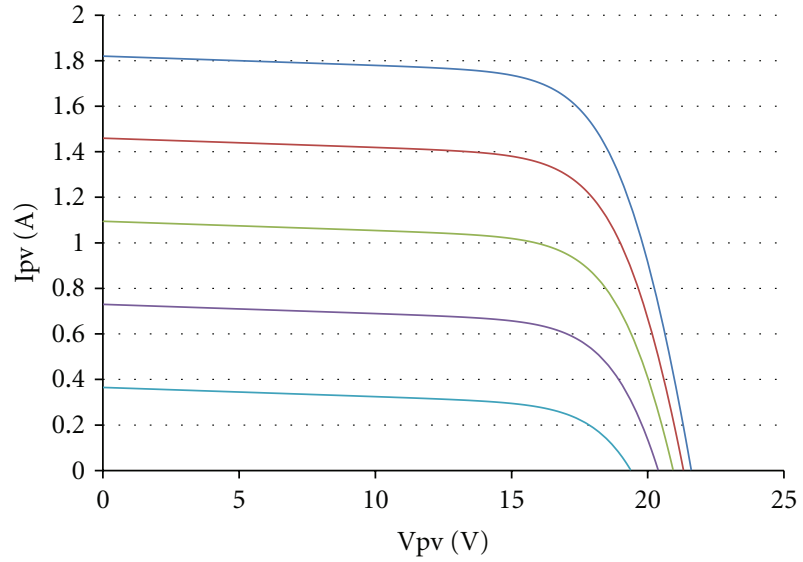

(a)

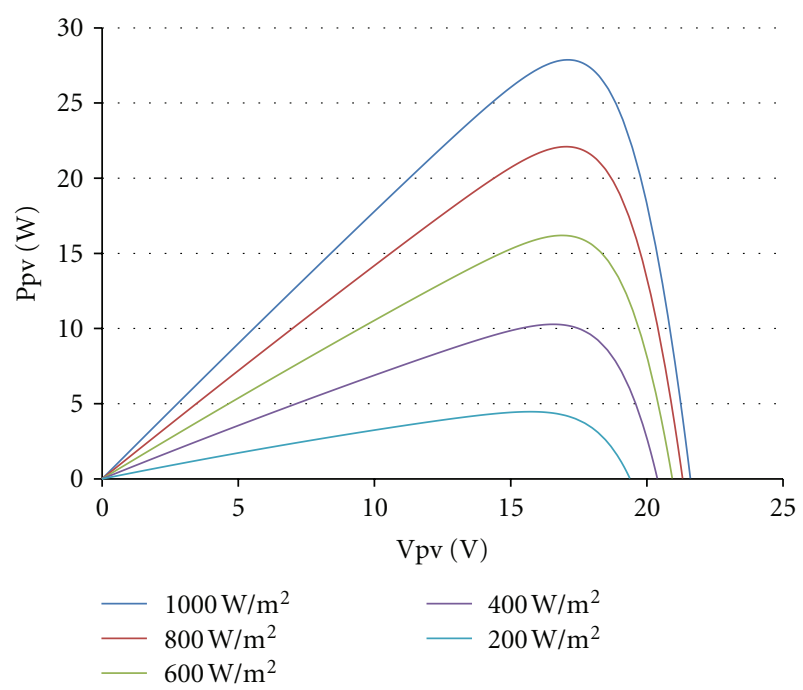

(b)

Figure 2: For a SANYO HIP 2717 module, (a) $I-V$, (b) $P$ - $V$ characteristic curves.

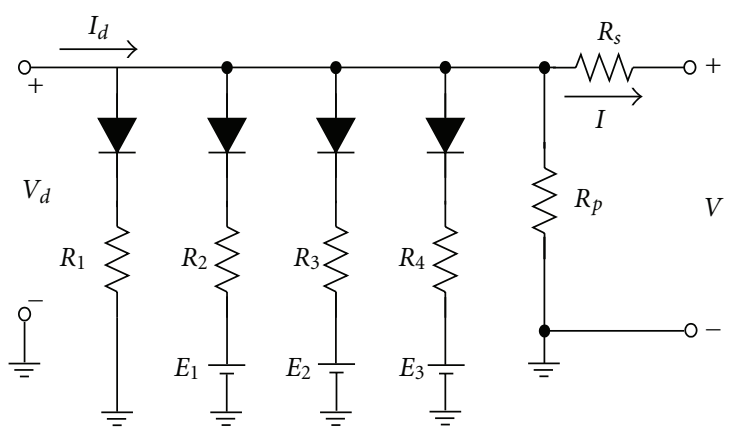

Figure 3: A solar cell model using a piecewise linear approximation.

of line segments, that is, a piecewise linear approximation. Yet, the simulation accuracy is highly affected by the number of such diodes, and a limited number of applications are found due to the reason that such model is merely applied to the so-called electromagnetic transients program (EMTP).

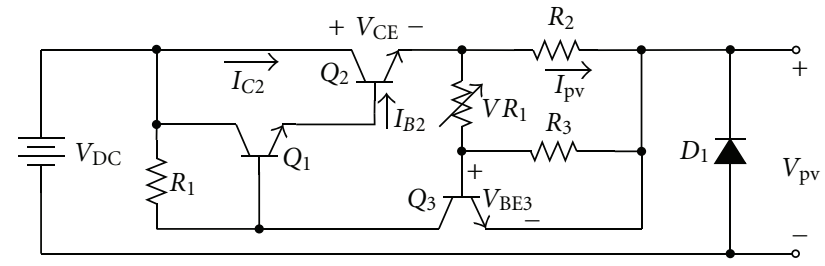

FIGURE 4: A test circuit for variable output characteristic simulations.

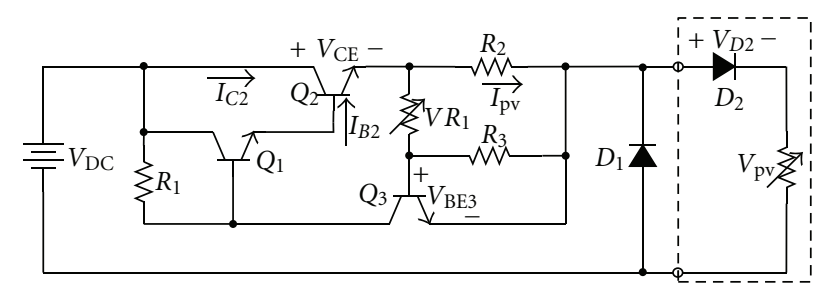

FIgURe 5: A test circuit for output characteristic simulation by a module simulator.

TABLE 1: Electrical specification for a SANYO HIP 2717 photovoltaic modules.

\begin{tabular}{lc}
\hline Name & Values \\
\hline Max. Power $\left(P_{\max }\right)$ & $27.87 \mathrm{~W}$ \\
Max. Power Current $\left(I_{\mathrm{mpp}}\right)$ & $1.63 \mathrm{~A}$ \\
Max. Power Voltage $\left(V_{\mathrm{mpp}}\right)$ & $17.1 \mathrm{~V}$ \\
Short Circuit Current $\left(I_{\mathrm{sc}}\right)$ & $1.82 \mathrm{~A}$ \\
Open Circuit Voltage $\left(V_{\mathrm{oc}}\right)$ & $21.6 \mathrm{~V}$ \\
Size $(\mathrm{mm})$ & $524 \times 496 \times 34$ \\
\hline
\end{tabular}

In [15], the module, connected in parallel/series, and the simulated $I-V$ as well as $P-V$ output characteristics are in good agreement with experiments. However, the model is made not taking into account the blocking and bypass diodes.

\section{Electric Circuit of a Simulator for Photovoltaic Modules}

Illustrated in Figure 4 is a hardware circuit of the module simulator capable of specifying output parameters. The circuit is one mainly composed of a Darlington pair, consisting of $Q_{1}, Q_{2}$ for current amplification, and an output current limiter, made up of $Q_{3}, V R_{1}, R_{2}, R_{3}$. The resistor $R_{2}$ is employed as a current detector, and a combination of $V R_{1}$ and $R_{3}$ as a voltage divider. For the purpose of the transistor $Q_{3}$ conduction, the voltage drop across $R_{2}$ increases with $V R_{1}$, leading to a rise in the output short circuit current. In order to test the output characteristic, the output end, as illustrated in Figure 4, is loaded with an electronic load, as Figure 5, through a continuous load variation all the way from the open circuit to the short circuit, for a complete measurement of a photovoltaic module.

In the determination of the modular short circuit current, $Q_{3}$ serves as a current limiting transistor. The transistor 
$Q_{3}$ is biased at the voltage level provided by the voltage divider, composed of $V R_{1}$ and $R_{3}$, connected in parallel with $R_{2}$. When once $V_{\mathrm{BE} 3}=V_{R 3} \cong 0.7 \mathrm{~V}, Q_{3}$ is then $\mathrm{ON}$, and $V_{\mathrm{BE} 3}$ is evaluated as

$$
V_{\mathrm{BE} 3}=V_{\mathrm{R}_{2}} \times \frac{R_{3}}{V R_{1}+R_{3}},
$$

where

$$
V_{\mathrm{R}_{2}}=I_{\mathrm{pv}} R_{2}
$$

The short circuit current is represented as

$$
I_{\mathrm{SC}}=I_{\mathrm{pv}}=V_{\mathrm{BE} 3} \times \frac{\left(V R_{1}+R_{3}\right)}{\left(R_{2} \times R_{3}\right)} .
$$

The voltage source $V_{\mathrm{DC}}$ is employed to tune the open circuit voltage. Once open circuited, the module is clamped by Q3 within the cutoff region at the output voltage

$$
V_{\mathrm{OC}}=V_{\mathrm{pv}}=V_{\mathrm{DC}}-V_{\mathrm{CE}(\mathrm{Q} 2)}-V_{\mathrm{D} 2} \text {, }
$$

where $V_{C E(Q 2)}$ is the crossed voltage between collector and emitter of the power transistor $Q_{2}$ as shown in Figure 5.

The bypass diode $D_{1}$ is employed as a component to prevent a "shadow" or "fault" in part of a module array, an assurance of electricity generation [18] as specified. Accordingly, the output characteristics of a photovoltaic module can be specified by electrical parameters.

\section{Simulation and Experimental Results}

5.1. Single Photovoltaic Module Output Characteristic. In the aspect of experiments, a SANYO HIP 2717 photovoltaic module is chosen as a test object for the comparison of $I-V$ as well as $P-V$ output characteristic between simulations and experiments. For a verification between the modular simulation and the electrical parameters agreement, the experiment is conducted firstly by altering the load resistance from $0 \Omega$ to $12 \mathrm{k} \Omega$, that is, the case from the short circuit to the open circuit. Subsequently, the $I-V$ and $P-V$ curves both are simulated by simulation packages Pspice and Solar Pro, then compared with experiments. Presented in Figures 6(a) and $6(\mathrm{~b})$ are the simulation results made for a single HIP 2717 module under standard test conditions (STCs). Error ratios of $3.8 \%$ and $10.17 \%$ for the maximum output are observed, respectively, between Pspice, Solar, and the experiments, with identical short circuit current of $1.82 \mathrm{~A}$ and open circuit voltage of $21.6 \mathrm{~V}$ as stated in a specification. By analysis, the slight variation in the maximal power point is presumed as a consequence of the deviation of transistor temperature effects between simulations and experiments. Regardless of the slight deviation, the experiments share the same tendency with the simulations, and there are marginal differences in the open circuit voltage and the short circuit current alike. Hence, the simulator proposed is proven as an accurate simulation tool.

5.2. Serial/Parallel Module Array Output Characteristic. In an attempt to explore the modular output characteristics, three

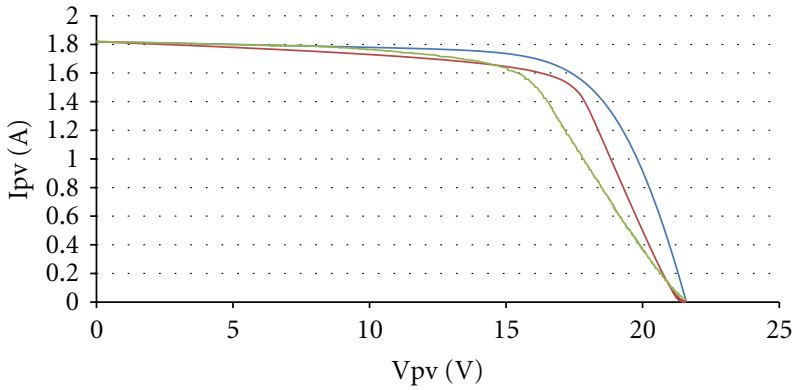

(a)

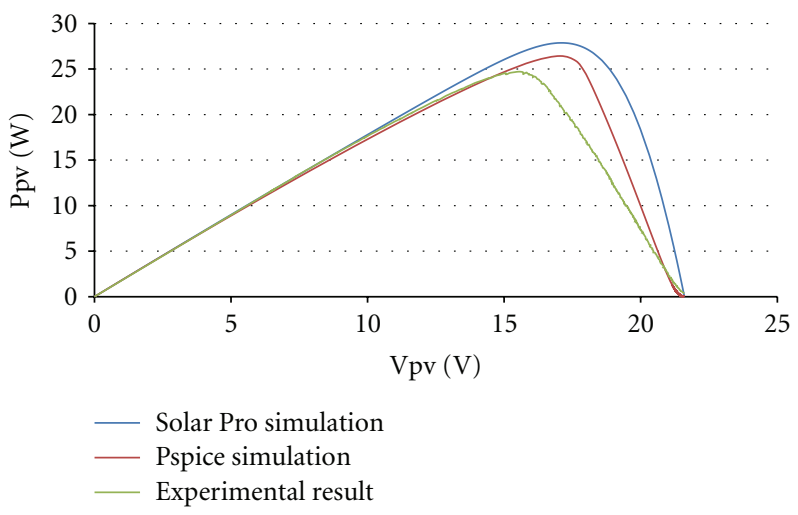

(b)

Figure 6: Comparison result for a single module, (a) $I-V$, (b) $P-V$ output characteristic curves.

array configurations are made by a small number of HIP 2717 modules, that is, 4 connected in series/ 1 in parallel, 1 in series/ 4 in parallel, and 2 in series/ 2 in parallel. As presented in Figures 7(a) and 7(b), a 4 in series/1 in parallel configuration is simulated by Pspice together with Solar Pro for an output $I-V$ and $P-V$ characteristics, from which error ratios of $3.7 \%$ and $10.02 \%$ in the maximal output power are found, while as in the preceding case in Figure 6, there are unnoticeable differences in the open circuit voltage and the short circuit current, and the same tendency is shared with the experimental result. It is as well found that such configuration provides not only an identical circuit current, but an open circuit voltage four times as high as that provided by a single module. In other words, it is a configuration applicable to a high-output voltage application.

In contrast, shown in Figures $8(\mathrm{a})$ and $8(\mathrm{~b})$ are the simulation results in the case of 1 in series/4 in parallel configuration. Analogous to the previous case, error ratios of $1.93 \%$ and $8.93 \%$ in the maximal output power are observed, and a small amount of deviation in the open circuit voltage and short circuit current together with a high tendency similarity is as well found. It is noted that such configuration offers the same open circuit voltage, but a short circuit current four times as high as that provided by a single module. That is, this configuration is suitable for a high-output current application.

For a further investigation into the remaining array configuration, a 2 in series/2 in parallel case is tested. As 


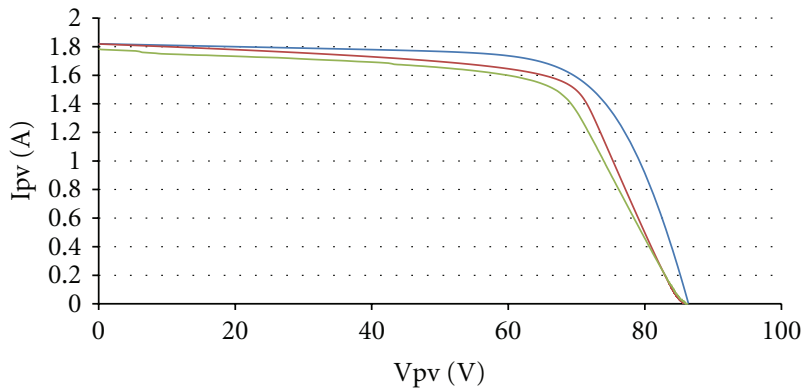

(a)

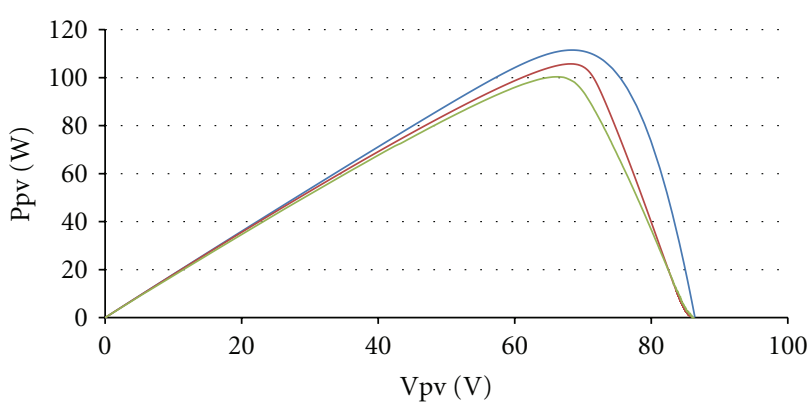

- Solar Pro simulation

— Pspice simulation

_ Experimental result

(b)

Figure 7: Comparison result for a 4 in series/ 1 in parallel module, (a) $I-V$, (b) $P-V$ output characteristic curves.

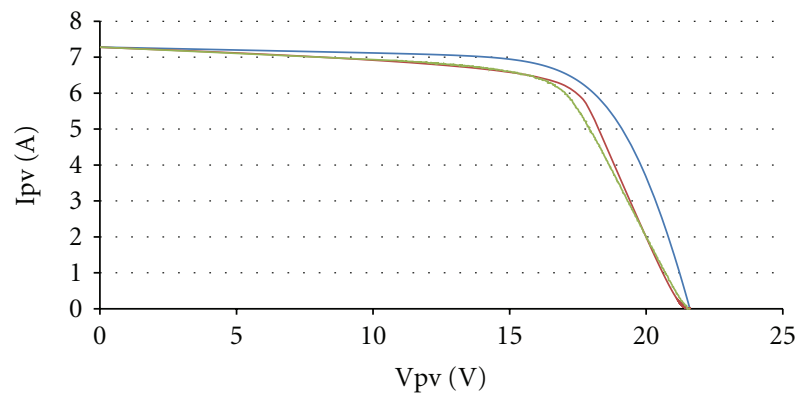

(a)

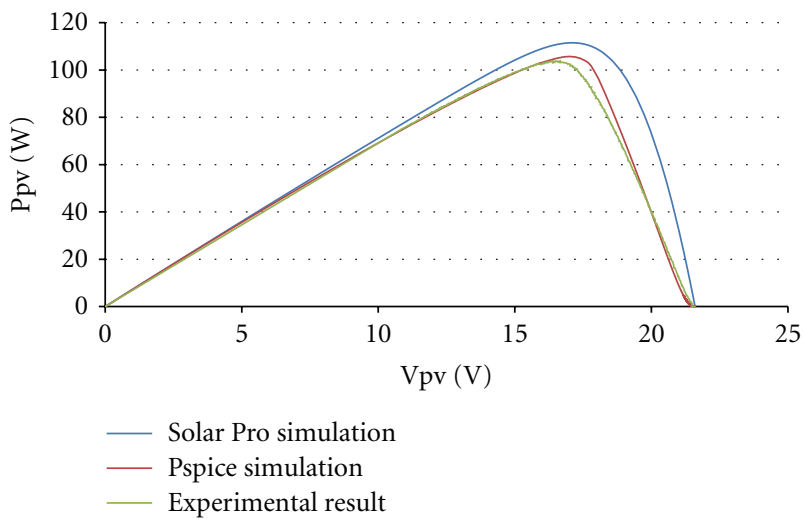

(b)

Figure 8: Comparison result for a 1 in series/4 in parallel module, (a) $I-V$, (b) $P-V$ output characteristic curves.

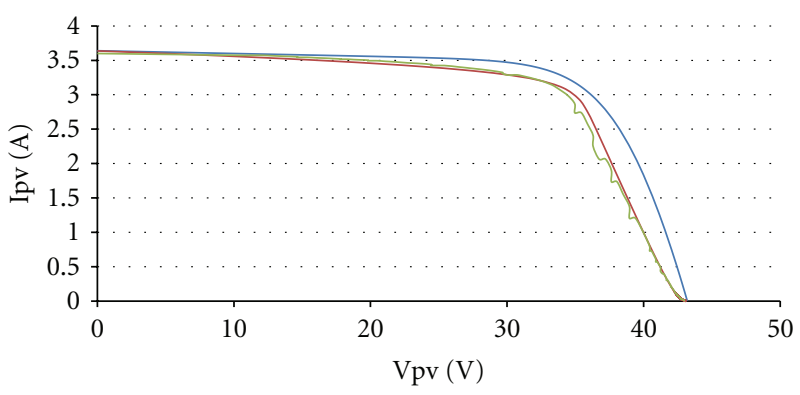

(a)

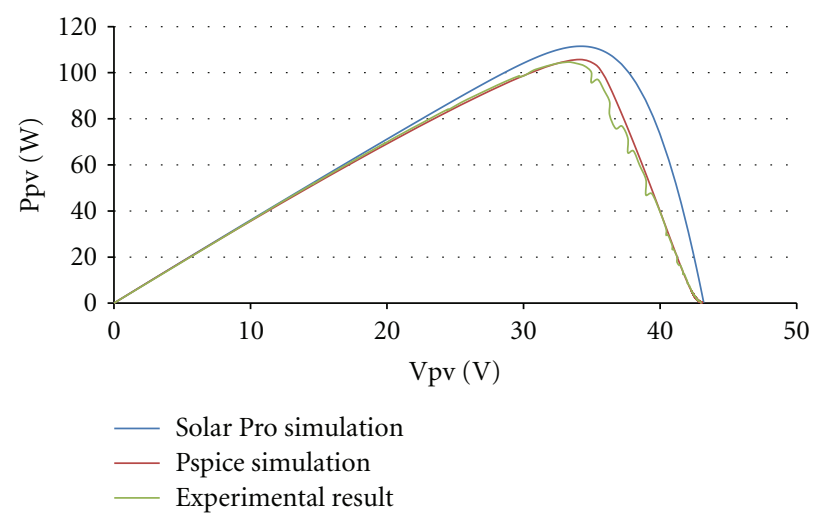

(b)

Figure 9: Comparison result for a 2 in series/ 2 in parallel module, (a) $I-V$, (b) $P-V$ output characteristic curves.

demonstrated in Figures 9(a) and 9(b), the simulation comparison is made between the experimental result, Pspice and Solar Pro. Error ratios of $0.95 \%$ and $7.14 \%$ in the maximum power point are gained, a small variation in the open circuit voltage as well as the short circuit current is seen, and an analogous tendency is as well found. It is noted from Figure 9 that such configuration exhibits a short circuit current and an open circuit voltage, both twice as high as those in the case of a single module. It is validated that such photovoltaic modular simulation is able to be configured in an arbitrary serial/parallel form to meet the output requirements.

\section{Conclusions}

Proposed in this work is an output characteristic simulator for a photovoltaic module, one not merely well describing high system nonlinearity, but also both the $I-V$ and $P-V$ output characteristics when modules are configured as an array. It is demonstrated as a superior simulator relative to simulation tools such as EMTP and PSIM, and as a tool in the course of an optimal experiment test in the implementation of a maximum power point tracking algorithm. Moreover, in terms of a circuit design, since the simulator does not involve any simulation package or programmable controller, the simulator is hence made easy to implement, with low cost and small size.

At present, most researches can only use circuit simulation or other software to explore the characteristics on 
various types of series-parallel connection and nonuniform irradiation for a photovoltaic module array. Although the error rates in the maximal output power seem too high as a consequence of deviation of power transistor temperature effects between software simulations and the proposed simulator, the simulator's experimental results share the same tendency with the software simulations, and there are marginal differences in the open circuit voltage and short current alike. Hence, the proposed simulator is proven as a useful experimental instrument for study of photovoltaic power generation systems.

\section{Acknowledgment}

This study was supported by funding from the National Science Council Project no. NSC100-3113-E007-006 courtesy of National Energy Technology Research Program, for which the authors would like to express their thanks.

\section{References}

[1] M. Park and I. K. Yu, "A novel real-time simulation technique of photovoltaic generation systems using RTDS," IEEE Transactions on Energy Conversion, vol. 19, no. 1, pp. 164-169, 2004.

[2] K. Khouzam, C. Ly, K. K. Koh, and Y. N. Poo, "Simulation and real-time modelling of space photovoltaic systems," in Proceedings of the 1st World Conference on Photovoltaic Energy Conversion, vol. 2, pp. 2038-2041, 1994.

[3] H. Yamashita, K. Tamahashi, M. Michihira, A. Tsuyoshi, K. Amako, and M. Park, "A novel simulation technique of the PV generation system using real weather conditions," in Proceedings of the Power Conversion Conference, vol. 2, pp. 839844,2002 .

[4] A. Zekry and A. Y. Al-Mazroo, "A distributed SPICE-model of a solar cell," IEEE Transactions on Electron Devices, vol. 43, no. 5, pp. 691-700, 1996.

[5] F. D. Ho and T. D. Morgan, "SPICE modeling of cascade solar cells," in Proceedings of IEEE Southeast Conference, pp. 776780, April 1991.

[6] M. F. Lamorte and D. H. Abbott, "Computer modeling of a two-junction, monolithic cascade solar concentration," IEEE Transactions on Electron Devices, vol. 27, no. 1, pp. 231-249, 1980.

[7] M. C. Glass, "Improved solar array power point model with SPICE realization," in Proceedings of the 31st Intersociety Energy Conversion Engineering Conference, pp. 286-291, August 1996.

[8] J. A. Gow and C. D. Manning, "Development of a photovoltaic array model for use in power-electronics simulation studies," IEE Proceedings: Electric Power Applications, vol. 146, no. 2, pp. 193-200, 1999.

[9] T. T. Lam, P. Malachesky, A. Garcia III, and E. Simburger, "Minimization of solar cell hot-spots on GPS solar arrays using saber modeling," in Proceedings of the 1st World Conference on Photovoltaic Energy Conversion, vol. 2, pp. 2042-2044, 1994.

[10] K. W. Horng, Measurement and EMTP modeling of photovoltaic cells applied to the analysis of partial shading faults, M.S. thesis, Department of Electrical Engineering, National Yunlin University of Science \& Technology, Taiwan, 2003.

[11] J. H. R. Enslin and D. B. Snyman, "Combined low-cost, highefficient inverter, peak power tracker and regulator for PV applications," IEEE Transactions on Power Electronics, vol. 6, no. 1, pp. 73-82, 1991.
[12] T. F. Elshatter, M. T. Elhagry, E. M. Abou-Elzahab, and A. A. T. Elkousy, "Fuzzy modeling of photovoltaic panel equivalent circuit," in Proceedings of the 28th IEEE Photovoltaic Specialists Conference, pp. 1656-1659, 2000.

[13] A. Al-Amoudi and L. Zhang, "Application of radial basis function networks for solar-array modelling and maximum powerpoint prediction," IEE Proceedings: Generation, Transmission and Distribution, vol. 147, no. 5, pp. 310-316, 2000.

[14] M. AbdulHadi, A. M. Al-Ibrahim, and G. S. Virk, "Neurofuzzy-based solar cell model," IEEE Transactions on Energy Conversion, vol. 19, no. 3, pp. 619-624, 2004.

[15] K. H. Chao, S. H. Ho, and M. H. Wang, "Modeling and fault diagnosis of a photovoltaic system," Electric Power Systems Research, vol. 78, no. 1, pp. 97-105, 2008.

[16] SANYO solar module HIP 2717 specification, Sanyo Solar Industries, http://us.sanyo.com/Solar.

[17] Y. J. Wang and P. C. Hsu, "Analysis of partially shaded PV modules using piecewise linear parallel branches model," in Proceedings of World Academy of Science, Engineering and Technology, vol. 60, pp. 783-789, 2009.

[18] K. D. Rasch and K. Roy, "Shunt and blocking diodes for protection of space solar cell arrays," in Proceedings of the IEEE PV Specialist's Conference, pp. 997-1000. 


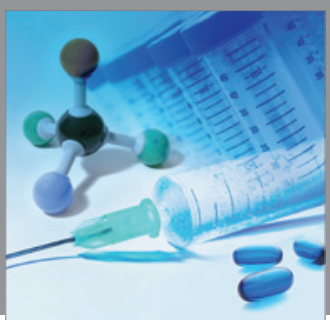

International Journal of

Medicinal Chemistry

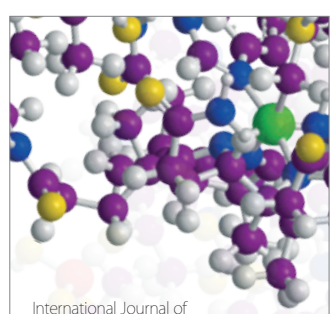

Carbohydrate Chemistry

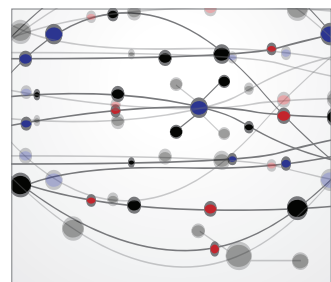

The Scientific World Journal
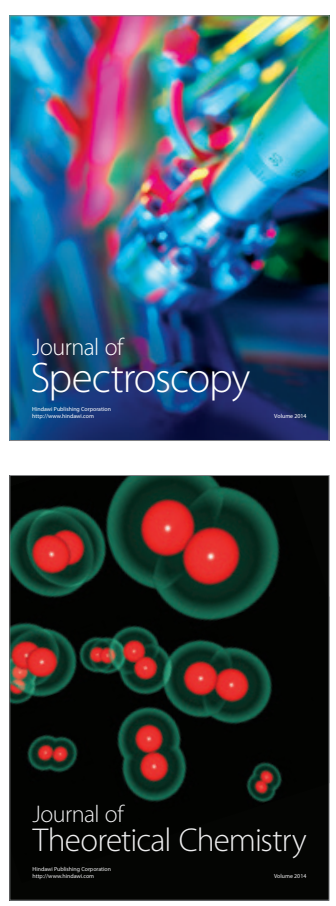
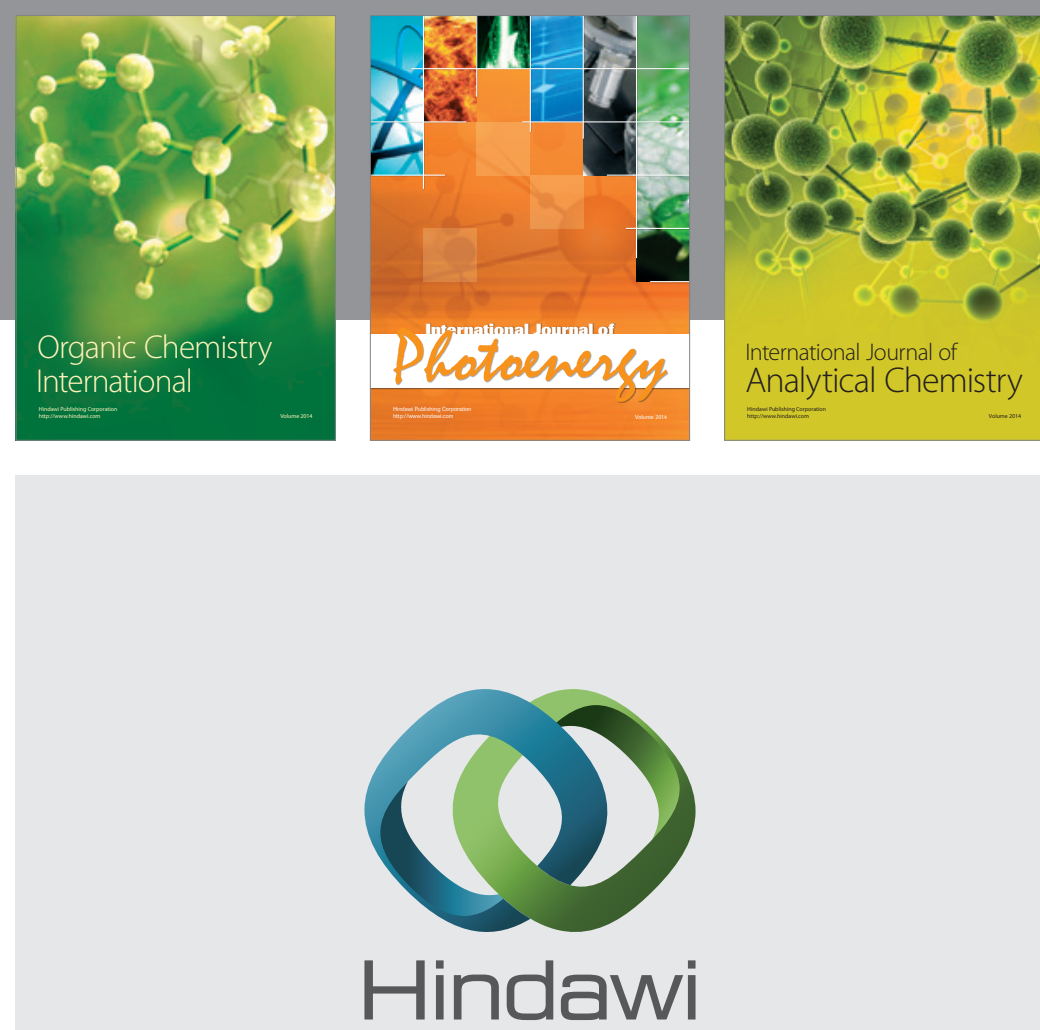

Submit your manuscripts at

http://www.hindawi.com
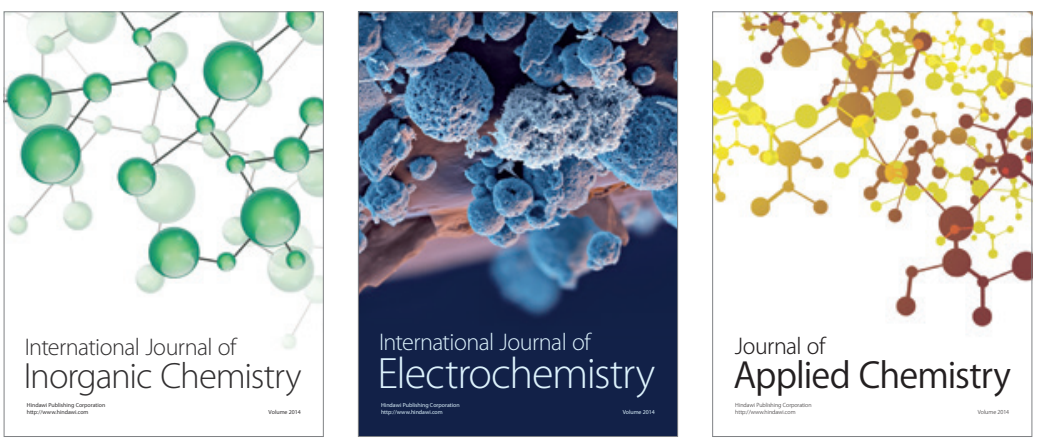

Journal of

Applied Chemistry
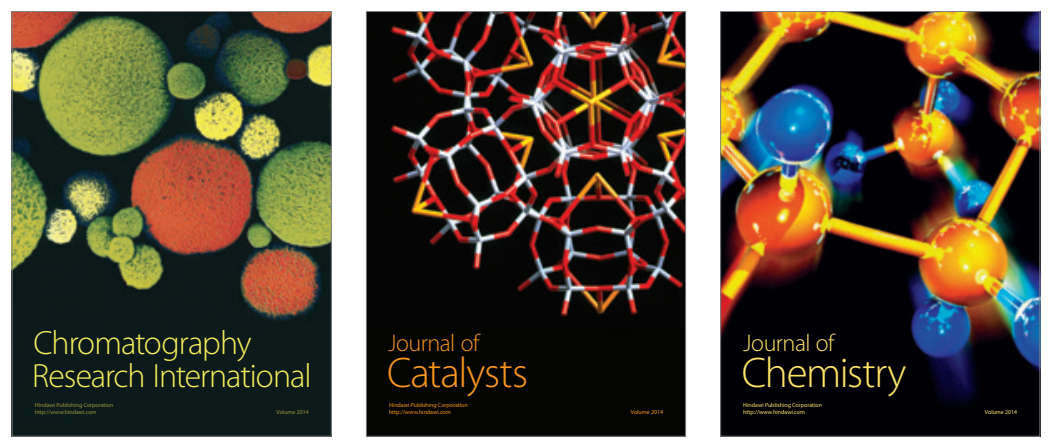
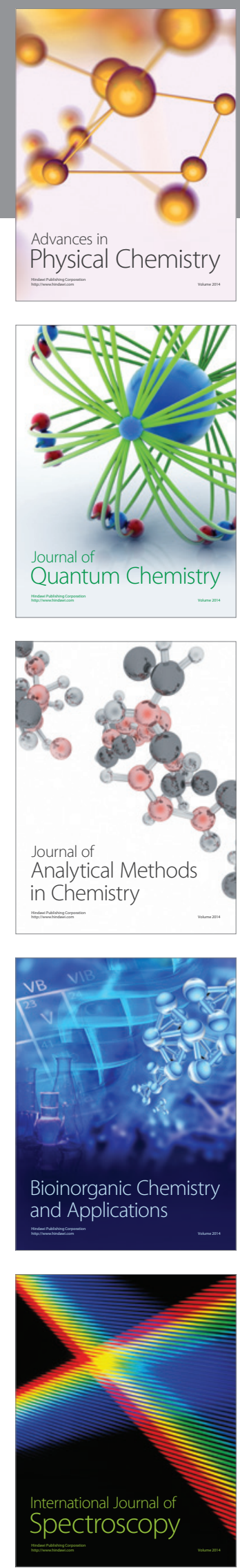